\title{
Hindcasts of Sea Level Variations during the 1982-83 El Niño
}

\author{
ANTONIO J. BUSALACCHI \\ Laboratory for Oceans, NASA/Goddard Space Flight Center, Greenbelt, MD 20771 \\ MARK A. CANE \\ Lamont-Doherty Geological Observatory, Palisades, NY 10964
}

15 May 1984 and 7 November 1984

ABSTRACT

\begin{abstract}
The sea level signature for the onset of the 1982-83 El Niño is hindcasted using a linear wind-driven model that consists of four vertical modes. The hindcast solution is compared with sea level time series from 18 island and coastal stations throughout the tropical Pacific. The response of the first and second baroclinic modes, when summed, account for a significant portion of the phase and amplitude of the observed sea level. The comparisons with observed sea level are best in the eastern tropical Pacific along the equator and South American coast where the solutions are a function of integrals of the zonal wind field to the west. The skill of the hindcast is notably less away from the equator.
\end{abstract}

\section{Introduction}

The El Niño event of $1982-83$ is one of the most dramatic occurrences of its kind on record. A great deal of just attention has been directed toward describing the oceanographic, atmospheric, and biologic characteristics of this phenomenon (Cane, 1983; Rasmusson et al., 1983; Barber and Chavez, 1983). Here we will be concerned with one aspect of the oceanographic character during 1982-83, namely, the basinwide sea level response to anomalous atmospheric conditions. The intent of this work is to hindcast the sea level recorded throughout the tropical Pacific basin for 1982 and early 1983, and thereby provide an indication of current capabilities to model the phase and amplitude of a specific sea level event using a simple ocean model.

Model hindcasts of the sea level response to estimates of the tropical Pacific wind field for specific years have been previously attempted by Busalacchi and O'Brien (1981) and Busalacchi et al. (1983). The results of these linear calculations accounted for a statistically significant portion of the phase of the observed sea level signal over a period of 18 years. However, the use of a single baroclinic mode and no allowance for post calculation parameter tuning precluded the possibility of obtaining sea level amplitudes comparable with those observed. Cane (1984) forced a linear model consisting of several baroclinic modes with wind field composites of six El Niño events. The model results and an accompanying discussion of theory demonstrated the significance of contributions to sea level from the gravest baroclinic modes.
The purpose of this note is to combine the approaches of the modeling studies cited above and perform a sea level hindcast involving wind stress estimates of a specific El Niño event and several baroclinic modes. This combination will permit both the phase and amplitude of the hindcast to be compared with an individual El Niño occurrence. Comparisons such as this were not possible in either the previous single mode or composite solutions.

The model used by Cane (1984) is used here to hindcast the onset of the 1982-83 El Niño event at 18 island and coastal stations. Calculations are performed for four baroclinic modes. Our primary concern is to determine how the quality of such a hindcast changes as a function of the individual modes being summed and not an analysis of the physical processes at work in 1982-83. (See Tang and Weisberg, 1984, for a process oriented discussion of the equatorial response to 1982-83 wind stress anomalies.) It is expected that summing several modes will increase the amplitude of the hindcasted sea level over that of a single mode solution. Whether any phase change caused by summing several modes improves the hindcast is also of interest. Cross correlations and root mean square (rms) differences between the hindcasted and observed sea levels are used as measures of the phase and amplitude differences.

\section{Model and data}

The model and supporting theory for this study have been described by Cane (1984) and Cane and 
Patton (1984). Briefly, the model is governed by the linear shallow water wave equations in which the low-frequency, long-wave approximation is invoked. The Kelvin wave contribution to the solution is determined by integrating along the characteristics. The contribution from long-wavelength Rossby waves is calculated using an implicit finite difference scheme on a $1^{\circ}$ longitude $\times 0.5^{\circ}$ latitude staggered grid. The numerical scheme is unconditionally stable so the time step is chosen to provide sufficient resolution for monthly forcing. A 10-day time step is used. The model basin is bounded by $124^{\circ} \mathrm{E}, 80^{\circ} \mathrm{W}, 20^{\circ} \mathrm{N}$, and $20^{\circ} \mathrm{S}$. A crude approximation to the coast of Mexico is formed by the removal of a $5^{\circ}$ latitude $\times 15^{\circ}$ longitude rectangle in the northeast corner of the basin.

The model is used to determine the wind-driven sea level response of the first four baroclinic modes during the 1982-83 El Niño. The modal decomposition is based on stratification data between $1.5^{\circ} \mathrm{N}$ and $1.5^{\circ} \mathrm{S}$ at $179^{\circ} \mathrm{W}$ as presented by Eriksen $e t$ al. (1983). The vicinity of the dateline is chosen because this was a region of anomalous wind variability in 1982-83 and previous El Niño years. The internal wave speeds for the four vertical modes are $c_{1}=2.90$ $\mathrm{m} \mathrm{s}^{-1}, c_{2}=1.77 \mathrm{~m} \mathrm{~s}^{-1}, c_{3}=1.13 \mathrm{~m} \mathrm{~s}^{-1}$, and $c_{4}$ $=0.84 \mathrm{~m} \mathrm{~s}^{-1}$.

The forcing function for the model calculation is the monthly mean surface wind stress fields for January, 1977 through March, 1983 provided by Dr. J. J. O'Brien. The analysis procedure of transforming individual ship-board wind observations into monthly wind stress fields on a $2^{\circ} \times 2^{\circ}$ grid is described by Goldenberg and O'Brien (1981). A drag coefficient of $1.5 \times 10^{-3}$ was used to compute the wind stress values. Beginning the calculation in January, 1977 provides an adequate spin-up time for low-latitude transients to die out. March of 1983 is the last month of the wind data set.

Descriptions of the anomalous surface wind field for the tropical Pacific are given by Sadler and
Kilonsky (1983a,b). In short, abnormally weak trade winds were characteristic of the equatorial Pacific during this period. Westerly anomalies were present west of the dateline during the boreal spring. A broad region of westerly anomalies then spread eastward reaching the eastern equatorial Pacific in early 1983.

Monthly means of the sea level contribution associated with each hindcast mode for January, 1982March, 1983 will form the basis for comparisons with the observed sea levels from the Pacific sea level network during the 1982-83 El Niño. Figure 1 indicates the locations of all the island and coastal stations for which we have obtained nearly continuous time series of monthly sea level from January, 1982 through March, 1983. Three of the 18 time series are incomplete. Data for Truk and Kwajalein Islands were only available for January-December, 1982. Linear interpolation is used to fill in missing sea levels for May, July, and August of 1982 in the Canton Island time series. Accounts of the observed coastal and equatorial sea level variabilities may be found in Enfield et al. (1983) and Wyrtki (1984).

\section{Results}

Upon completion of the model calculation the sea level response of each individual baroclinic mode and all possible sums of modes were analyzed with respect to the observed sea level of each station. Figure 2 depicts the monthly mean sea levels recorded at Santa Cruz in the Galapagos Islands and hindcasted by the four-mode sum of the model solution. A scaling analysis based on the stratification data used here (cf. Cane, 1984) implies that the total sea level response is dominated by contributions from the first and second baroclinic modes. Figure 3 shows the individual contribution of each mode to the model solution for Santa Cruz. It is clearly seen that the major contribution to the phase and amplitude of the total solution is from the first and second baroclinic modes. The contribution from the third and fourth modes is

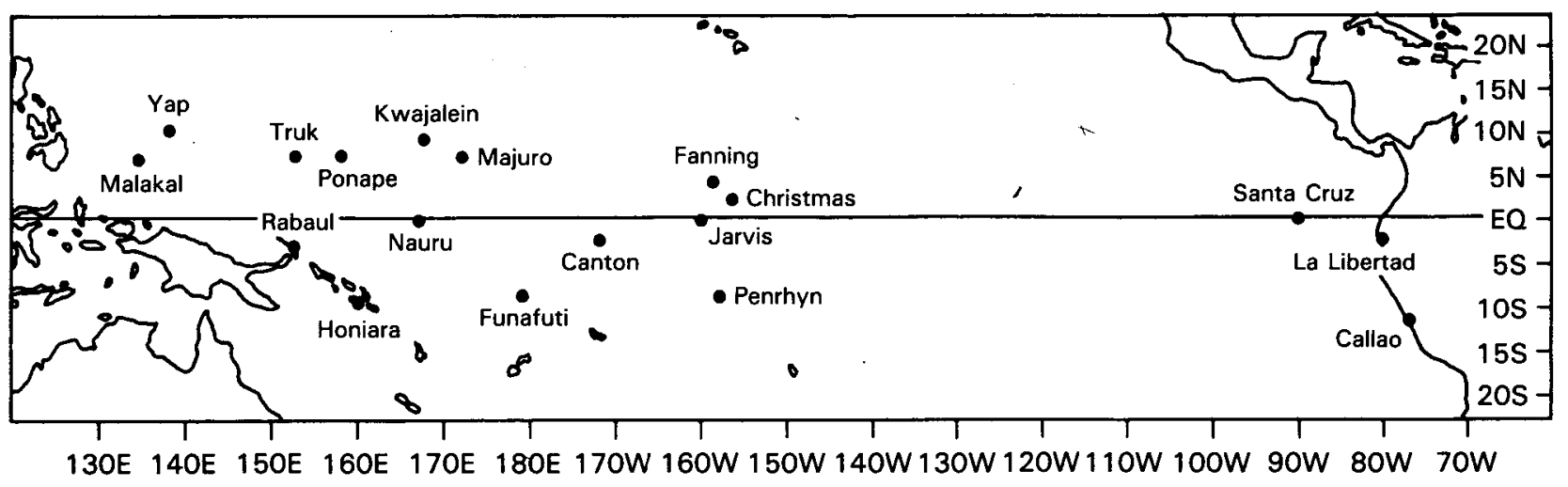

FIG. 1. Island and coastal stations for which sea level data was available from January 1982-March 1983. 


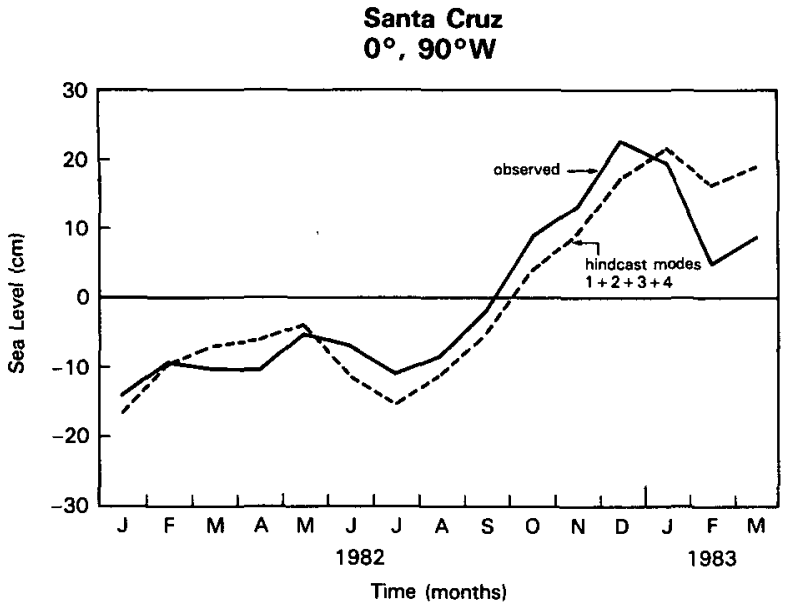

FIG. 2. Sea level (cm) observed at Santa Cruz (solid line) and hindcasted by modes $1+2+3+4$ (dashed line). Both curves are plotted as deviations about the mean for the record length presented.

at most $6 \mathrm{~cm}$ and is only noticeable when the first and second modes are small. This decrease in amplitude from the second to the third to the fourth mode is representative of all the stations. Statistical analyses to be discussed below also indicate the influence of the third or fourth mode is negligible when comparing the sum of the lowest order modes with observed sea level.

Superpositions of the time series for the observed sea level and the hindcast sum of the first and second baroclinic modes at all stations are indicated in Fig. 4. The first panel (Fig. 4a) contains all the coastal and near-equatorial stations ordered by longitude. The second panel contains the remaining stations of higher latitudes. In what follows, comparisons of the model hindcast and observed sea level will be presented for the coast of South America, at islands west along the equator, and ending with locations off the equator. Next, the cross correlations and rms differences will be discussed.

The amplitude and phase of the model hindcast are most similar to the observed sea level variability in the eastern tropical Pacific. For the first 6 months of 1982 the observed and modeled variability are characterized by $10-15 \mathrm{~cm}$ sea level changes of one to two months duration. During the second half of 1982 there is a dramatic $30-40 \mathrm{~cm}$ rise in sea level in both records denoting the onset of the El Niño event. The rapid sea level increase in the model solution is a response to anomalous westerly winds along the equator. The 6-month increase in sea level is followed by a $15-20 \mathrm{~cm}$ drop in observed sea level and a $10 \mathrm{~cm}$ decrease in hindcasted sea level in 1983 . Daily sea level records indicate this drop in sea level occurred over a 1-2 week period in January. Similar comparisons (not shown) also hold for the coastal stations of Paita $\left(5^{\circ} \mathrm{S}\right)$ and Chimbote $\left(12^{\circ} \mathrm{S}\right)$ because of the high degree of spatial coherence that is both observed along the coast of South America and required by theory in the model calculation.

The most prominent aspect of the observed sea level variability in the central equatorial Pacific (Christmas, Fanning, Jarvis, and Canton Islands) is the sustained elevated sea level from July to December resulting from an increase in sea level that began in

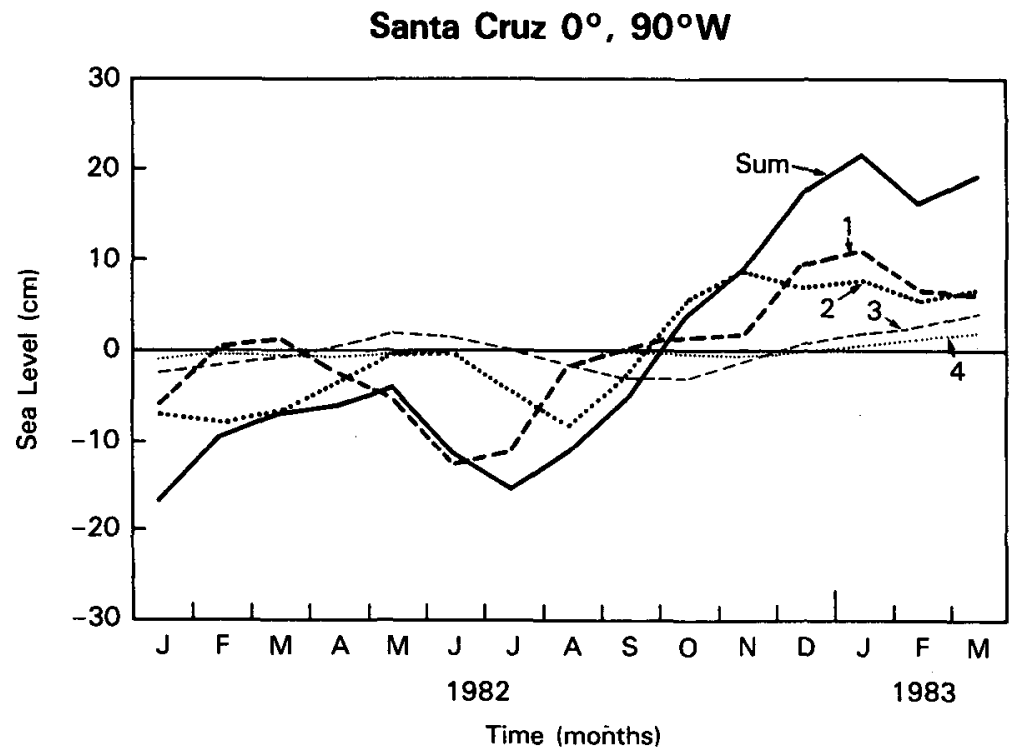

FIG. 3. Contribution of each individual mode to the four-mode hindcast at Santa Cruz. 1st mode: dashed line; 2nd mode: dotted line; 3rd mode: light dashed line; 4th mode: light dotted line. 

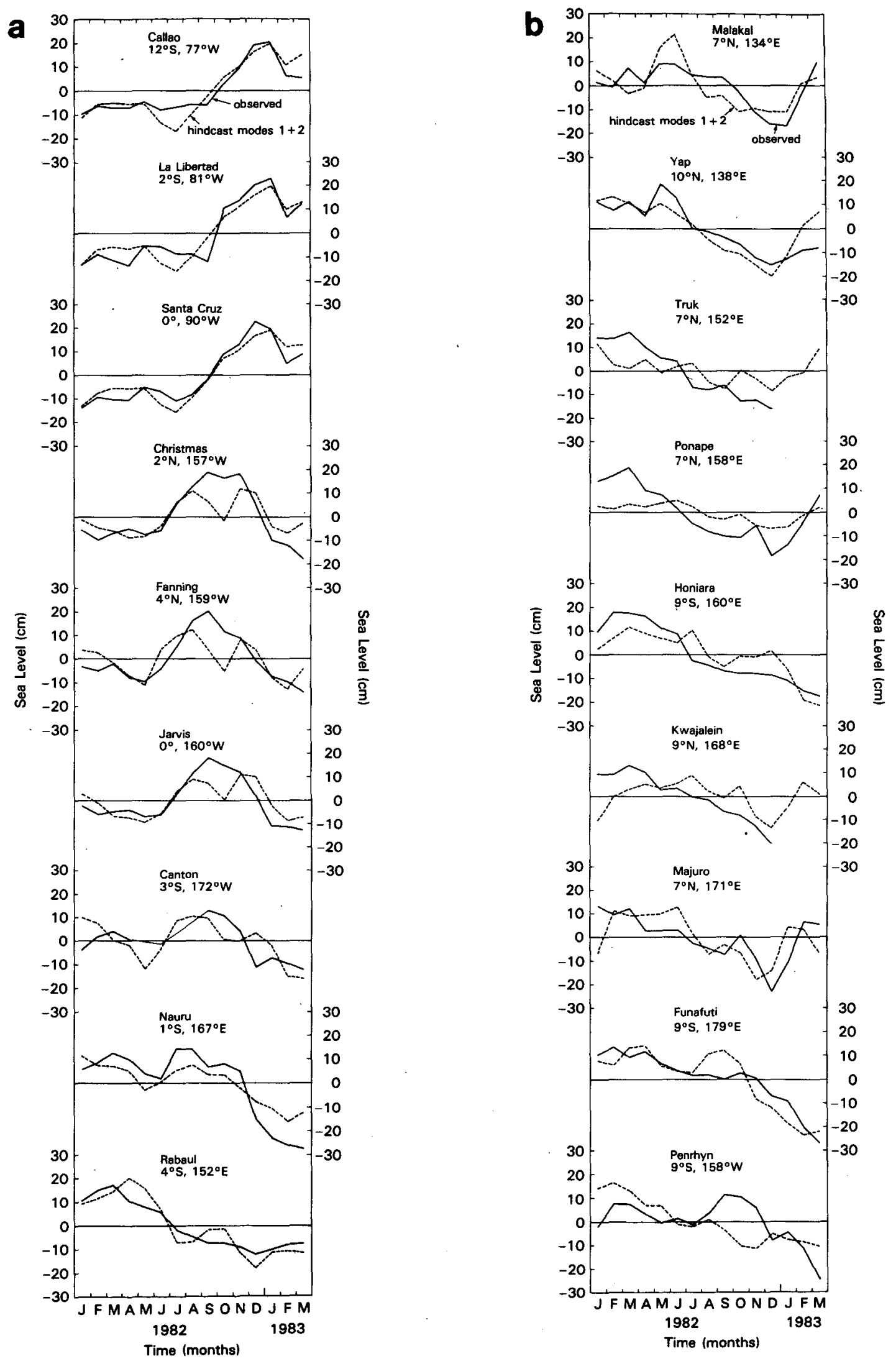

FIG. 4. Sea level (cm) observed at 18 island and coastal stations (solid line) and hindcasted by modes $1+2$ (dashed line): (a) equatorial and coastal stations ordered by longitude and (b) off-equatorial stations. Note that observed sea levels were not available for May, July, and August 1982 at Canton Island and January-March 1983 at Truk and Kwajalein Islands. 
May. A major shortcoming of the model hindcast in this region is the decrease in sea level from August to October that separates two short episodes of elevated sea level. This discrepancy is associated with a first baroclinic mode response to a decrease in the westerly forcing function west of the dateline. An increase in the amplitude of the sea level depression away from the equator is also suggestive of a secondary influence from westward propagating Rossby waves in response to westerly anomalies to the east. Prior to and after this period the phase and amplitude of the hindcast are in better agreement with the observed sea level for the three islands near $160^{\circ} \mathrm{W}$. (It is difficult to compare at Canton Island because sea level data are missing for key months.) Without additional wind observations it is difficult to determine if this difference is due to an error in the wind estimates. In the eastern tropical Pacific this first mode sea level decrease generated west of the dateline negates a sea level increase caused by westerly anomalies in the central and eastern Pacific. A relatively constant first mode contribution to sea level from August to November results (Fig. 3).

At the western equatorial stations and locations off the equator, the hindcast results indicate a decreasing trend in sea level similar to that observed for most of 1982. This drop in sea level, which is out of phase with the sea level in the east, is representative of an eastward transfer of mass in response to the westerly wind anomalies of 1982 . For time scales shorter than 6 months there are several examples of significant phase and amplitude differences.

Cross correlations and rms differences have been computed to quantify the comparisons between the hindcasted and observed sea level. These statistics provide a quantitative measure of the visual comparisons although the limited record length results in a low number of degrees of freedom. The statistics were found for each individual mode and the 11 possible combinations of two, three, or four modes. (The single mode statistics and the combinations of most interest are given in Tables 1 and 2 of the Appendix.) This will enable a determination of how the amplitude and phase differences between the observations and the hindcast change from one mode to another, as the modes are summed, and as a function of location.

For single mode solutions the maximum positive correlations with observed sea level are associated with the first or second mode of the hindcast at 15 out of the 18 stations. Only at Kwajalein, Ponape, and Canton Islands do the third or fourth modes have the highest correlation. At 12 of the stations the maximum correlation is for the second mode with lag near zero. Similar results hold for the rms difference between each mode and observed sea level. The rms difference is smallest for the first or second mode at all locations except Ponape Island. At 13 of the stations the rms difference is smallest for the second mode.

When summing modes the most notable improvement to the statistics is provided by the sum of the first and second modes. At 14 of the stations the correlation increases and/or the rms difference decreases when this sum is compared with the best single mode values. There is no significant change in the phase or amplitude difference when modes 1,2 , and 3 or modes $1,2,3$ and 4 are summed instead. The influence of the third and fourth modes is negligible for these and all other combinations of modes.

Figure 5 gives the geographical distribution of the maximum cross correlations and scaled rms differences between observed sea level and the model hindcast with mode 1 plus mode 2 . The largest correlation coefficients are at the coast of South America and on the equator at the eastern and western extremes of the basin. All the maximum correlations occur at zero lag except for the five stations (Fanning, Majuro, Canton, Kwajalein, and Penrhyn) with the lowest correlations. The rms differences have been scaled by the standard deviations about the record mean of the observed sea level.

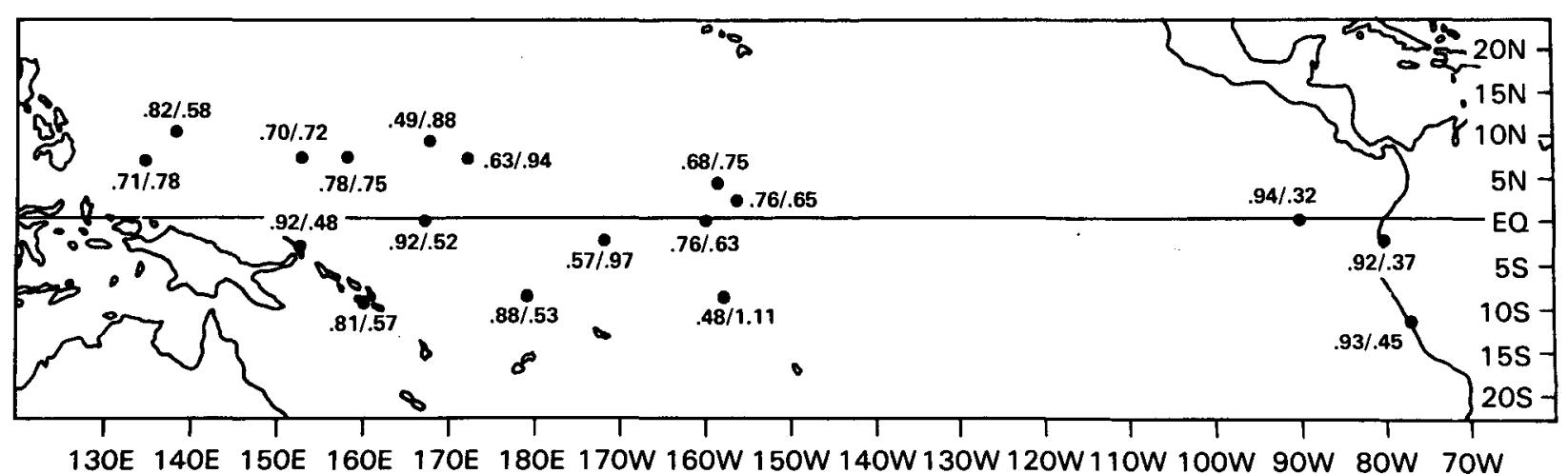

FIG. 5. Cross correlations/scaled rms differences between observed sea level and the hindcast sum of modes 1 and 2. Each rms difference is scaled by the standard deviation of the observed sea level. 
Thus large rms differences are not necessarily associated with large amplitude sea level changes. (The unscaled rms values are in Table 2 of the Appendix.) Except for Penrhyn Island, the rms difference at each station is less than the standard deviation of the observed sea level. Scaling the rms differences permits one to see that the locations with the highest correlations also have the lowest $\mathrm{rms}$ differences, i.e., the smallest rms differences are at the South American coastal stations and on the equator at both ends of the basin.

A remaining point of interest in these results is whether the hindcasts can be substantially improved by "tuning" various model parameters. We seek to determine if the amplitude and phase differences between the hindcasted and observed sea level can be reduced by varying the amplitudes of the individual modes being summed or by changing the drag coefficient of the wind stress. To determine the effect of changing the individual amplitudes of the hindcast modes, the sea level response of each mode is used as input to step-wise linear regression models of the observed sea level. Consistent with the previous statistics the regression analysis indicates the third and fourth modes are seldom significant at the $95 \%$ level even when the unrealistically generous assumption that each month is mutually independent is used. As expected, the results of the multi-mode regression models with the first two modes do little to improve the phase errors between the hindcast and observations since many of the cross correlations of Table 1 are already quite high, primarily due to the second mode. Nonetheless, modifying the amplitudes of modes 1 and 2 can result in a $20 \%$ decrease in the rms difference. The best fit with the observed sea level at the three eastern tropical Pacific locations is obtained by multiplying the amplitude of the first mode by $0.58-0.65$ and by multiplying the second mode amplitude by $0.95-1.51$ depending on the station. The rms differences for single mode solutions can be reduced by a similar percentage with multiplicative factors of 0.7-2.9. However, no single change in modal amplitude can improve the results over those of the unmodified sum of the first and second modes.

The question of changing the value of the drag coefficient is addressed by adding the mode 1 and mode 2 responses and then performing the regression analysis on the sum. At 16 of the 18 locations the rms differences are reduced by roughly the same amount as above. At Kwajalein and Penrhyn, where the previous statistics were poor, no significant improvement can be made. The range of the regression coefficients is $0.50-2.39$ with 10 stations falling in a narrower range of $0.76-1.27$. There is no apparent geographic distribution to these coefficients. If each station is given equal weight the average of the regression coefficients is 1.03 , which is an a posteriori implication that this specific hindcast study could not be substantially improved by altering the drag coefficient chosen.

\section{Discussion}

The aim of this note is to provide an indication of our current capabilities to hindcast the amplitude and phase of a specific sea level event throughout the tropical Pacific Ocean using a simple ocean model. Previous attempts to model the wind-driven response of the tropical Pacific Ocean indicate a significant portion of the phase of the observed sea level signal can be modeled using a single baroclinic mode given a reasonable estimate of the surface wind field. Such single mode solutions however underestimate the amplitude of the sea level signal. Here we have modeled the responses of the four gravest baroclinic modes to wind changes from January 1982-March 1983. Comparisons with sea level time series for 18 stations across the tropical Pacific are used to test the quality of the hindcast and determine which combination of modes provides the best fit with the data.

This work differs from that of Busalacchi and O'Brien (1981) as the total sea level response is found by summing the amplitude of several baroclinic modes. The approach in this study also differs with Cane (1984) in that simultaneous forcing and sea level data are used as opposed to composite means. Due to these differences the phase and amplitude of these hindcasts are in much better agreement with the observed sea level than in the previous studies.

At most of the stations the highest cross correlations and the lowest rms differences between the hindcasted and observed sea level are for the sum of the first and second baroclinic modes. Summing the first and second modes allows sea level amplitudes to be obtained that are comparable with the observed sea level. The influence of the second mode also improves the phase of the hindcast over that of only the first mode. The contribution of the third and fourth modes is insignificant when compared to the first two modes. At the present level of hindcast skill the errors inherent in estimating the wind field and in using a constant vertical structure are likely to have a greater impact on the quality of the hindcast than these higher order modes. Of the four single mode solutions, the second baroclinic mode has the smallest amplitude and phase differences with the observed sea level records. Yet, changing the amplitude of any single mode will not provide statistics as good as the sum of the first and second modes.

Geographically, the hindcast provides the best fit with observed sea level at the coastal stations of South America and on the equator in the eastern and western extremes of the basin. A reasonable depiction of the phase and amplitude of the onset of the El Niño event is hindcasted for the eastern tropical Pacific. A concomitant decrease in sea level in the 
west is also modeled. The failure of the hindcast to account for the magnitude of the sea level decrease in early 1983 suggests a need for increased temporal resolution of the wind field as daily sea level measurements indicate this occurred over a 1-2 week period. The maximum cross correlations with observed sea level are greater than 0.90 at zero lag and the rms differences with observed sea level are onethird to one-half the standard deviation of the observed sea level variability.

The quality of the hindcast is degraded at locations in the central equatorial Pacific and off the equator. A major discrepancy between the observed and hindcasted sea levels for the central equatorial Pacific in August to October, 1983 is traced back to a diminution of the westerly anomalies forcing the model west of the dateline. The hindcasts for the island stations outside the equatorial zone consist primarily of a long-term decrease in sea level similar to that recorded at several islands. However, at these locations sea level events of a few months duration are not well modeled. The range of cross correlations is $0.48-0.88$ with lags of 0 or \pm 1 month. The rms differences vary from 0.53 to 1.11 times the standard deviation of the observed sea level. There is nothing systematic about the distribution of these statistics for the nonequatorial locations. At some points agreement is good, while at other points which should be dynamically similar the agreement is disparate (e.g. Funafuti and Penrhyn). This suggests that an incorrect forcing field is at fault.

The dynamics of the wind-driven response on the equator is simple. In the east, the coastal and equatorial solutions are determined by equatorially trapped Kelvin waves impinging on the eastern boundary. The amplitude of this response is governed by integrals of the zonal wind stress along the equator to the west (cf. Cane, 1984). The primary influence for the western equatorial sea level can be described in terms of westward-propagating Rossby waves. The solutions away from the equator are slightly more complex and therefore more prone to error. The solutions in these regions are influenced by a derivative of the forcing, i.e., the wind stress curl. Any random errors present in the wind estimates are apt to have a greater influence under differentiation than integration.

In summary, a significant portion of the phase and amplitude of the sea level variability during the onset of the 1982-83 El Niño is hindcasted using a linear wind-driven model. The responses of the first and second baroclinic modes, when summed, result in a sea level signal comparable with that observed. The comparisons are best in the eastern tropical Pacific along the equator and South American coast where the solutions are a function of integrals of the zonal wind field to the west.

Sea level is, loosely speaking, a vertically integrated variable that tends to average out nonlinear, nonadiabatic effects. The model is dynamically simple, but it is unlikely that a more sophisticated model would improve the agreement in sea level. Increased spatial and temporal resolution of the wind field is needed for that. Hence we do not expect that observations of sea level will be able to discriminate between simple linear theory and more sophisticated models of ocean physics. On the other hand, equatorial currents and near surface isotherm displacements are thought to be significantly influenced by nonlinear effects (e.g., observational evidence in Lukas, 1981; theoretical arguments in Charney, 1960; many other examples could be given). Further, according to linear theory, these variables are more strongly dependent on higher mode responses than is sea level (McCreary, 1981). Consideration of these less integrated variables will be required to validate models more complex than the linear wind-driven one discussed here.

Acknowledgments. The authors wish to thank J. J. O'Brien (F.S.U.) for graciously providing the wind data. Special thanks to K. Wyrtki (U.H.) for providing the sea level data from the Pacific sea level network and to D. Enfield (O.S.U.) and S. P. Hayes (P.M.E.L.) for the coastal sea level data. The programming assistance rendered by Mark Terman and Bill Hurlin is gratefully acknowledged. This work was supported by a NOAA grant under the EPOCS program and NASA RTOP 161-20-31. 


\section{APPENDIX}

TABLE 1. Cross correlations between observed sea level and the hindcast solutions indicated. Positive lag indicates model lags observed sea level.

\begin{tabular}{|c|c|c|c|c|c|c|c|c|c|c|c|c|}
\hline \multirow[b]{2}{*}{ Location } & \multicolumn{2}{|c|}{ Mode 1} & \multicolumn{2}{|c|}{ Mode 2} & \multicolumn{2}{|c|}{ Mode 3} & \multicolumn{2}{|c|}{ Mode 4} & \multicolumn{2}{|c|}{ Modes $1+2$} & \multicolumn{2}{|c|}{$\begin{array}{c}\text { Modes } \\
1+2+3+4 \\
\end{array}$} \\
\hline & $r$ & Lag & $r$ & Lag & $r$ & Lag & $r$ & Lag & $r$ & Lag & $r$ & Lag \\
\hline $\begin{array}{l}\text { Callao } \\
12^{\circ} \mathrm{S}, 77^{\circ} \mathrm{W}\end{array}$ & 0.78 & 0 & 0.85 & 0 & 0.63 & 2 & 0.76 & 2 & 0.93 & 0 & 0.90 & 0 \\
\hline $\begin{array}{l}\text { La Libertad } \\
2^{\circ} \mathrm{S}, 81^{\circ} \mathrm{W}\end{array}$ & 0.72 & 0 & 0.91 & 0 & 0.56 & 2 & 0.69 & 2 & 0.92 & 0 & 0.92 & 0 \\
\hline $\begin{array}{l}\text { Santa Cruz } \\
0^{\circ}, 90^{\circ} \mathrm{W}\end{array}$ & 0.78 & 0 & 0.91 & 0 & 0.60 & 2 & 0.76 & 2 & 0.94 & 0 & 0.92 & 0 \\
\hline $\begin{array}{l}\text { Christmas } \\
2^{\circ} \mathrm{N}, 157^{\circ} \mathrm{W}\end{array}$ & -0.52 & -7 & 0.84 & 0 & -0.81 & -2 & -0.58 & -8 & 0.76 & 0 & 0.70 & 0 \\
\hline $\begin{array}{l}\text { Fanning } \\
4^{\circ} \mathrm{N}, 159^{\circ} \mathrm{W}\end{array}$ & 0.66 & -1 & -0.60 & 5 & -0.88 & -2 & -0.70 & -3 & 0.68 & -1 & 0.60 & 0 \\
\hline $\begin{array}{l}\text { Jarvis } \\
0^{\circ}, 160^{\circ} \mathrm{W}\end{array}$ & -0.53 & -6 & 0.88 & 0 & -0.85 & -2 & -0.45 & -9 & 0.76 & 0 & 0.73 & 1 \\
\hline $\begin{array}{l}\text { Canton } \\
3^{\circ} \mathrm{S} 172^{\circ} \mathrm{W}\end{array}$ & 0.61 & -1 & 0.54 & 1 & 0.80 & -6 & 0.65 & -3 & 0.57 & -1 & 0.57 & -1 \\
\hline $\begin{array}{l}\text { Nauru } \\
1^{\circ} \mathrm{S}, 167^{\circ} \mathrm{E}\end{array}$ & 0.83 & 0 & 0.73 & 0 & 0.66 & -3 & -0.62 & -12 & 0.92 & 0 & 0.89 & 0 \\
\hline $\begin{array}{l}\text { Rabaul } \\
4^{\circ} \mathrm{S}, 152^{\circ} \mathrm{E}\end{array}$ & 0.75 & 1 & 0.96 & 0 & 0.75 & 4 & 0.87 & 0 & 0.92 & 0 & 0.92 & 0 \\
\hline $\begin{array}{l}\text { Malakal } \\
7^{\circ} \mathrm{N}, 134^{\circ} \mathrm{E}\end{array}$ & 0.56 & 0 & 0.71 & -2 & 0.67 & -9 & -0.53 & -1 & 0.71 & 0 & 0.70 & 0 \\
\hline $\begin{array}{l}\text { Yap } \\
10^{\circ} \mathrm{N}, 138^{\circ} \mathrm{E}\end{array}$ & 0.59 & 0 & 0.89 & -1 & 0.35 & 0 & -0.79 & -1 & 0.82 & 0 & 0.82 & 0 \\
\hline $\begin{array}{l}\text { Truk } \\
7^{\circ} \mathrm{N}, 152^{\circ} \mathrm{E}\end{array}$ & 0.56 & 3 & 0.74 & -2 & 0.51 & 2 & 0.34 & 1 & 0.70 & 0 & 0.71 & 0 \\
\hline $\begin{array}{l}\text { Ponape } \\
7^{\circ} \mathrm{N}, 158^{\circ} \mathrm{E}\end{array}$ & 0.53 & 3 & -0.48 & -11 & 0.88 & 1 & 0.74 & 0 & 0.78 & 0 & 0.82 & 0 \\
\hline $\begin{array}{l}\text { Honiara } \\
9^{\circ} \mathrm{S}, 160^{\circ} \mathrm{E}\end{array}$ & 0.60 & 0 & 0.88 & 1 & -0.58 & 0 & 0.76 & 0 & 0.81 & 0 & 0.81 & 0 \\
\hline $\begin{array}{l}\text { Kwajalein } \\
9^{\circ} \mathrm{N}, 168^{\circ} \mathrm{E}\end{array}$ & 0.46 & 1 & -0.47 & -4 & 0.59 & -3 & 0.77 & 0 & 0.49 & 1 & 0.52 & 1 \\
\hline $\begin{array}{l}\text { Majuro } \\
7^{\circ} \mathrm{N}, 171^{\circ} \mathrm{E}\end{array}$ & 0.72 & -1 & 0.65 & 3 & 0.62 & 2 & -0.42 & -4 & 0.63 & -1 & 0.63 & -1 \\
\hline $\begin{array}{l}\text { Funafuti } \\
9^{\circ} \mathrm{S}, 179^{\circ} \mathrm{E}\end{array}$ & 0.79 & 0 & 0.94 & 0 & 0.61 & 0 & -0.50 & -2 & 0.88 & 0 & 0.89 & 0 \\
\hline $\begin{array}{l}\text { Penrhyn } \\
9^{\circ} \mathrm{S}, 158^{\circ} \mathrm{W}\end{array}$ & -0.49 & -13 & 0.66 & -1 & 0.61 & -1 & 0.63 & -1 & 0.48 & -1 & 0.50 & -1 \\
\hline
\end{tabular}

TABLE 2. The rms differences $(\mathrm{cm})$ between observed sea level and the hindcasted solutions indicated. The standard deviation (S.D.) of observed sea level is included for comparison.

\begin{tabular}{|c|c|c|c|c|c|c|c|}
\hline Location & Mode 1 & Mode 2 & Mode 3 & Mode 4 & $\begin{array}{l}\text { Modes } \\
1+2\end{array}$ & $\begin{array}{c}\text { Modes } \\
1+2+3+4\end{array}$ & $\begin{array}{l}\text { S.D. observed } \\
\text { sea level }\end{array}$ \\
\hline $\begin{array}{l}\text { Callao } \\
12^{\circ} \mathrm{S}, 77^{\circ} \mathrm{W}\end{array}$ & 6.0 & 5.5 & 9.0 & 9.3 & 4.5 & 5.8 & 9.9 \\
\hline $\begin{array}{l}\text { La Libertad } \\
2^{\circ} \mathrm{S}, 81^{\circ} \mathrm{W}\end{array}$ & 9.0 & 7.3 & 11.8 & 12.2 & 4.8 & 5.0 & 13.0 \\
\hline $\begin{array}{l}\text { Santa Cruz } \\
0^{\circ}, 90^{\circ} \mathrm{W}\end{array}$ & 7.7 & 6.6 & 11.2 & 11.3 & 3.9 & 5.2 & 12.1 \\
\hline
\end{tabular}


TABLE 2. (Continued).

\begin{tabular}{|c|c|c|c|c|c|c|c|}
\hline Location & Mode 1 & Mode 2 & Mode 3 & Mode 4 & $\begin{array}{c}\text { Modes } \\
1+2\end{array}$ & $\begin{array}{c}\text { Modes } \\
1+2+3+4\end{array}$ & $\begin{array}{l}\text { S.D. observed } \\
\text { sea level }\end{array}$ \\
\hline $\begin{array}{l}\text { Christmas } \\
2^{\circ} \mathrm{N}, 157^{\circ} \mathrm{W}\end{array}$ & 11.0 & 8.3 & 12.5 & 11.6 & 7.8 & 8.4 & 12.0 \\
\hline $\begin{array}{l}\text { Fanning } \\
4^{\circ} \mathrm{N}, 159^{\circ} \mathrm{W}\end{array}$ & 8.2 & 8.7 & 10.6 & 9.8 & 7.7 & 8.0 & 10.3 \\
\hline $\begin{array}{l}\text { Jarvis } \\
0^{\circ}, 160^{\circ} \mathrm{W}\end{array}$ & 8.9 & 6.6 & 10.5 & 9.7 & 6.3 & 7.1 & 10.0 \\
\hline $\begin{array}{l}\text { Canton } \\
3^{\circ} \mathrm{S}, 172^{\circ} \mathrm{W}\end{array}$ & 7.5 & 6.4 & 8.5 & 7.2 & 7.5 & 7.8 & 7.7 \\
\hline $\begin{array}{l}\text { Nauru } \\
1^{\circ} \mathrm{S}, 167^{\circ} \mathrm{E}\end{array}$ & 10.3 & 12.0 & 13.9 & 14.1 & 7.8 & 7.5 & 14.9 \\
\hline $\begin{array}{l}\text { Rabaul } \\
4^{\circ} \mathrm{S}, 152^{\circ} \mathrm{E}\end{array}$ & 6.6 & 4.1 & 9.5 & 9.2 & 4.8 & 4.9 & 9.9 \\
\hline $\begin{array}{l}\text { Malakal } \\
7^{\circ} \mathrm{N}, 134^{\circ} \mathrm{E}\end{array}$ & 7.1 & 6.7 & 8.4 & 8.4 & 6.8 & 6.9 & 8.6 \\
\hline $\begin{array}{l}\text { Yap } \\
10^{\circ} \mathrm{N}, 138^{\circ} \mathrm{E}\end{array}$ & 8.3 & 5.9 & 10.2 & 10.4 & 6.2 & 6.3 & 10.6 \\
\hline $\begin{array}{l}\text { Truk } \\
7^{\circ} \mathrm{N}, 152^{\circ} \mathrm{E}\end{array}$ & 12.2 & 9.2 & 11.2 & 11.4 & 8.5 & 8.4 & 11.9 \\
\hline $\begin{array}{l}\text { Ponape } \\
7^{\circ} \mathrm{N}, 158^{\circ} \mathrm{E}\end{array}$ & 10.4 & 11.0 & 10.4 & 10.9 & 8.5 & 7.9 & 11.4 \\
\hline $\begin{array}{l}\text { Honiara } \\
9^{\circ} \mathrm{S}, 160^{\circ} \mathrm{E}\end{array}$ & 9.4 & 8.6 & 11.9 & 11.7 & 7.0 & 6.9 & 12.2 \\
\hline $\begin{array}{l}\text { Kwajalein } \\
9^{\circ} \mathrm{N}, 168^{\circ} \mathrm{E}\end{array}$ & 9.1 & 8.8 & 9.6 & 9.6 & 8.9 & 8.7 & 10.2 \\
\hline $\begin{array}{l}\text { Majuro } \\
7^{\circ} \mathrm{N}, 171^{\circ} \mathrm{E}\end{array}$ & 8.1 & 9.4 & 9.3 & 9.4 & 9.1 & 9.0 & 9.7 \\
\hline $\begin{array}{l}\text { Funafuti } \\
9^{\circ} \mathrm{S}, 179^{\circ} \mathrm{E}\end{array}$ & 6.7 & 7.1 & 10.8 & 11.0 & 6.1 & 5.7 & 11.4 \\
\hline $\begin{array}{l}\text { Penrhyn } \\
9^{\circ} \mathrm{S}, 158^{\circ} \mathrm{W}\end{array}$ & 11.0 & 7.1 & 8.7 & 8.9 & 10.5 & 10.8 & 9.4 \\
\hline
\end{tabular}

\section{REFERENCES}

Barber, R. T., and F. P. Chavez, 1983: Biological consequences of El Niño. Science, 222, 1203-1210.

Busalacchi, A. J., and J. J. O'Brien, 1981: Interannual variability of the equatorial Pacific in the 1960's. J. Geophys. Res., 86, 10901-10907.

, K. Takeuchi and J. J. O'Brien, 1983: Interannual variability of the equatorial Pacific-Revisited. J. Geophys. Res., 88, $7551-7562$.

Cane, M. A., 1983: Oceanographic events during El Niño. Science, 222, 1189-1195.

- 1984: Modeling sea level during El Niño. J. Phys. Oceanogr., 14, 1864-1874.

- and R. J. Patton, 1984: A numerical model for the lowfrequency equatorial dynamics. $J$. Phys. Oceanogr., 14, 18531863.

Charney, J. G., 1960: Non-linear theory of a wind-driven homogenous layer near the equator. Deep-Sea Res., 6, 303-310.

Enfield, D. B., R. L. Smith and S. P. Hayes, 1983: Sea level variability at the eastern equatorial Pacific boundary in 1982 . Trop. Ocean-Atmos. Newslett., 21, 13-14.

Eriksen, C. C., M. B. Blumenthal, S. P. Hayes and P. Ripa, 1983: Wind-generated equatorial Kelvin waves observed across the Pacific Ocean. J. Phys. Oceanogr., 13, 1622-1640.
Goldenberg, S. B., and J. J. O'Brien, 1981: Time and space variability of tropical Pacific wind stress. Mon. Wea. Rev., 109, 1190-1207.

Lukas, R., 1981: The termination of the Equatorial Undercurrent in the eastern Pacific. Ph.D. dissertation, University of Hawaii, $127 \mathrm{pp}$.

McCreary, J. P., 1981: A linear stratified ocean model of the Equatorial Undercurrent. Phil. Trans. Roy. Soc. London, A298, 603-535.

Rasmusson, E. M., P. A. Arkin, A. F. Krueger, R. S. Quiroz and R. W. Reynolds, 1983: The equatorial Pacific atmospheric climate during 1982-83. Trop. Ocean-Atmos. Newslett., 21, 2-3.

Sadler, J. C., and B. J. Kilonsky, 1983a: Meteorological events during evolution of positive SST anomalies in the eastern Pacific in 1982. Trop. Ocean-Atmos. Newslett., 16, 3-4.

- , and B. J. Kilonsky, 1983b: Meteorological events in the central Pacific during 1983 associated with the 1982-83 El Niño: Trop. Ocean-Atmos. Newslett., 21, 3-5.

Tang, T. Y., and R. H. Weisberg, 1984: On the equatorial Pacific response to the 1982/83 El Niño-Southern Oscillation event. J. Mar. Res., 42, 809-829.

Wyrtki, K., 1984: Pacific-wide sea level fluctuations during the 1982-83 El Niño. Galapagos 1982-1983: A chronicle of the effects of the "El Niño", G. Robinson and E. del Pino, Eds. 